\title{
Une littérature de la domination religieuse
}

À propos de :Ebied Rifaat \& Herman Teule, (éd.), Studies on the Christian Arabic Heritage, Leuven, Peeters, 2004.Ebied Rifaat \& David Thomas, (éds.), Muslim-Christian Polemic during the Crusades. The Letter from the People of Cyprus and Ibn Abî Țālib al-Dimashqî̀s Response, Leiden, Brill, 2005.Van Ginkel Jan J., Heleen H.L. Murre-Van den Berg \& Theo M. Van Lint, (éds.), Redefining Christian Identity. Cultural Interaction in the Middle East since the Rise of Islam, Leuven, Peeters, 2005.Zaborowski Jason R., The Coptic Martyrdom of John of Phanijôit. Assimilation and Conversion to Islam in Thirteenth-Century Egypt, Leiden, Brill, 2005.

\section{Christian Décobert}

\section{(2) OpenEdition Journals}

\section{Édition électronique}

URL : http://journals.openedition.org/assr/11303

DOI : 10.4000/assr. 11303

ISSN : $1777-5825$

Éditeur

Éditions de l'EHESS

Édition imprimée

Date de publication : 1 décembre 2007

Pagination : 91-117

ISBN : 978-2-7132-2145-3

ISSN : 0335-5985

Référence électronique

Christian Décobert, "Une littérature de la domination religieuse », Archives de sciences sociales des religions [En ligne], 140 | octobre - décembre 2007, mis en ligne le 02 juillet 2008, consulté le 02 mai 2019. URL : http://journals.openedition.org/assr/11303 ; DOI : 10.4000/assr.11303 


\title{
Christian Décobert
}

\section{Une littérature de la domination religieuse}

\author{
À propos de : \\ Ebied Rifaat \& Herman Teule, (éd.), Studies on the Christian Arabic \\ Heritage, Leuven, Peeters, 2004. \\ Ebied Rifaat \& David Thomas, (éds.), Muslim-Christian Polemic \\ during the Crusades. The Letter from the People of Cyprus and \\ Ibn Ab̂̀ Tălib al-Dimashqî’s Response, Leiden, Brill, 2005. \\ Van Ginkel Jan J., Heleen H.L. Murre-Van den Berg \& Theo M. van \\ LINT, (éds.), Redefining Christian Identity. Cultural Interaction in \\ the Middle East since the Rise of Islam, Leuven, Peeters, 2005. \\ ZABOROwski Jason R., The Coptic Martyrdom of John of Phanijôit. \\ Assimilation and Conversion to Islam in Thirteenth-Century Egypt, \\ Leiden, Brill, 2005.
}

Les chrétiens du monde musulman médiéval sont à la mode. Ils offrent l'avantage d'ouvrir à des questions historiques, mais aussi très contemporaines, relatives à l'identité, à la frontière religieuse, au fait communautaire. Ces chrétiens, qui n'étaient certes pas si lointains, ont livré une documentation riche mais encore largement inexploitée. Pour autant, la bibliographie de cette dernière décennie sur les coptes d'Égypte, les maronites du Mont Liban, les melkites de Syrie, les nestoriens d'Irak, etc., est devenue importante, et elle témoigne - tout autant que d'un effet de simple mode - d'une évidente volonté de renouvellement de ce morceau de l'histoire médiévale, celle des chrétiens que nous appelons « orientaux », sous domination musulmane. Les documents sur lesquels s'appuient de telles études sont essentiellement des textes littéraires, au sens où ils ont été généralement rédigés au sein d'un corps spécialisé de lettrés et qu'ils étaient voués à une certaine diffusion dans ce même univers de lettrés. Certains de ces textes étaient déjà connus au début $\mathrm{du} \mathrm{XX}^{\mathrm{e}}$ siècle, voire au $\mathrm{XIX}^{\mathrm{e}}$ siècle, déjà édités et traduits, d'autres sont exhumés aujourd'hui. Ils constituent un corpus très homogène d'œuvres apologétiques et de controverse, auxquelles s'ajoutent quelques récits historiographiques et hagiographiques.

Il convient certainement de s'interroger sur ce que de tels textes disent réellement, que ce soit de façon directe ou indirecte. Directement, ils expriment des convictions, 
des prescriptions, ils développent une argumentation empreinte d'une rhétorique très formalisée, ils racontent des histoires toujours édifiantes : ils expriment les valeurs des milieux de leur production. Mais, indirectement, ils peuvent informer sur la manière dont les convictions et les prescriptions étaient exprimées, dont les arguments étaient formulés, sur les précautions, les usages codés ou métaphoriques de certaines formes démonstratives, ils renseignent sur les faits d'intertextualité, sur la façon dont tel texte était travaillé, traversé par d'autres textes, dont il absorbait certains de leurs traits formels, dont il recevait et entérinait certaines de leurs procédures rhétoriques. En bref, ils peuvent en dire beaucoup sur le capital culturel, religieux, de leurs auteurs. Cette information indirecte est d'une importance préjudicielle pour l'historien, et elle doit être recueillie prioritairement et dans la durée. Il s'agit là d'un contrat d'étude qui mêle les niveaux, et qui vise à écrire une histoire sociale d'une certaine production littéraire religieuse - chrétienne, soumise à la lancinante pression d'un islam triomphant. Or ce contrat n'est pas toujours entièrement rempli. Nombre de travaux se limitent à l'information directe: ils présentent l'édition (et souvent la traduction) d'un texte, lequel est commenté pour les idées qu'il défend. D'autres, plus rares, relèvent les faits d'intertextualité. Plus rares encore sont ceux qui mettent en situation historique un ensemble de textes, afin de tenter de percevoir les transformations, les ruptures, les faits d'héritage et de renoncement, et d'apporter les éléments nécessaires à une histoire de la perception et de la circulation de ce que l'on qualifiera malaisément comme les «idées religieuses ».

Mais, en soi, le fait même que le contrat ne soit pas souvent rempli peut être interrogé. Qu'est-ce qui, en définitive, fait que l'on s'en tient fréquemment à l'écume du sens immédiat des textes étudiés ? Permettons-nous d'exprimer d'emblée un soupçon que nous nous proposons d'étayer ensuite : est-ce qu'une telle retenue ne serait pas largement stratégique? Est-ce qu'éclairer d'une lumière crue les faits d'intertextualité n'obligerait pas à conclure à une certaine pauvreté d'idées, toujours répétées, voire ressassées, à une absence au long terme de renouvellement théorique, doctrinal, dans les milieux lettrés chrétiens ? Est-ce que cette retenue ne serait pas parfois guidée par une réticence à reconnaître ce qui devrait être reconnu, c'est-à-dire que le christianisme dit « oriental » s'est fortement enkysté, que son capital de pensée, de dogme et de croyance ne s'est pas reproduit tel quel au long des siècles, qu'il a été proprement phagocyté par un islam terriblement présent, et prégnant ? En d'autres termes, c'est une certaine orientation disciplinaire, inhérente aux études dites "chrétiennes ", qui semble devoir être interrogée. À cet égard, les quelques ouvrages présentés ici nous paraissent très représentatifs de la production actuelle.

Les débuts de l'apologétique chrétienne, dans les pays soumis à la domination politique de l'islam, datent du VIII siècle. L'étude synthétique de Sidney Griffith (2005) est une excellente entrée en matière à ce que l'on considère communément comme un genre littéraire à part entière. La figure éponyme de cet exorde est 
évidemment Jean Damascène (ob. avant 754), qui est célébré pour avoir très clairement reconnu le défi que représentait l'islam et avoir exprimé la nécessité qu'il y avait à le relever. Un texte fameux contre l'islam (habituellement qualifié comme la " $101^{\mathrm{e}}$ hérésie de Jean Damascène ») lui est faussement attribué, mais Sidney Griffith a raison de dire que la pseudo signature de Jean importe peu, puisqu'il a été effectivement produit dans le milieu melkite syrien du VIII siècle, dans lequel vivait le moine de Saint-Sabas. Mais l'important est la logique soulevée par cette attribution obligée à l'homme de la doctrine et de la traque des hérésies, par laquelle il n'y avait pas d'apologie possible du christianisme sans controverse, il n'y avait plus d'œuvre conséquente sur le christianisme sans qu'elle ne comprît les traces d'un regard - hostile, inquiet - sur ce qui était désormais terriblement présent : l'islam.

Les circonstances sont connues. L'islam apparut comme une religion, aux yeux des lettrés chrétiens, à l'extrême fin du VII siècle. L'édification du Dôme du Rocher de Jérusalem a été comme la marque soudaine et ostensible de l'autonomie de l'islam, comme nouvelle religion parmi les monothéismes abrahamiques. Daté de 691/692, sous le califat omeyyade de 'Abd al-Mâlik ibn Marwân, le Dôme signifiait, en ce lieu très sacré, la revendication abrahamique des Arabesmusulmans, mais surtout fondait la distinction de l'islam sur un monothéisme absolu qui rejetait les dogmes de la Trinité et de la divinité du Christ, qui intégrait la figure de Jésus dans une prophétologie scellée par Muhammad. Il s'adressait enfin aux vaincus de la conquête, en usant de leurs propres figures symboliques, pour exalter la supériorité d'une religion d'hommes vainqueurs, qui s'appropriaient l'un des lieux fondateurs du monothéisme révélé (Grabar, 1959). Les écrits d'Anastase le Sinaïte (qui d'ailleurs évoque la construction du Dôme en l'attribuant aux démons...) témoignent de cette inquiétude (Flusin, 1991), comme certains textes d'Apocalypse en syriaque et en copte (Suermann, 2004). L'islam posait un redoutable problème, dans la mesure où il était explicitement vu comme une religion possiblement mangeuse d'âmes : les premières Apocalypses chrétiennes d'époque arabe parlent de la nation arabe comme prédatrice, infiniment avide de richesses, mais aussi comme tentatrice, attirant ceux qui sont attachés aux biens de ce monde ; les apologues d'Anastase évoquent les conversions à l'islam de prisonniers de guerre, de gens de condition servile. Certes, les gouvernants arabes ne cherchaient nullement à convertir, se contentant d'administrer des hommes avec lesquels la distinction ontologique s'imposait. Et il est vrai que les conversions furent rares au VIII ${ }^{\mathrm{e}}$ siècle, ne concernant que des individus qui avaient un intérêt immédiat à passer dans le camp des régnants, comme des administrateurs civils ou religieux, des mercenaires, des prisonniers, des serviteurs. Mais, bien que peu significatives en nombre, ces conversions frappaient les esprits attentifs, au point qu'une littérature de «ressaisissement » vit le jour. Dès les premières Apocalypses, une représentation éthique de la domination arabe était imposée (Décobert, 1992). Les Arabes sont d'essence démoniaque, mais la conquête arabe 
eut comme cause l'état de péché des chrétiens, leur manque de piété, leur surdité aux commandements de Dieu. Ainsi les Arabes sont à la fois mus par la puissance satanique et des instruments de la volonté de Dieu. Ils sont là pour punir les pécheurs et faire que leur rédemption sera possible, et si ces pécheurs comprennent leur malheur présent et font contrition, alors le salut leur sera accordé, et les Arabes seront vaincus, chassés de leurs terres. La littérature eschatologique ou apologétique, dès le VIII ${ }^{\mathrm{e}}$ siècle, se voulait donc réactive, armée de prévarication, brandissant l'éthique et la lumière de la rédemption.

\section{Arguments de la controverse}

Au plan doctrinal, une littérature de défense et illustration du christianisme apparut parallèlement. Mais précisément, s'il s'agissait de défendre et conséquemment d'attaquer, quel en était le contexte? Qu'est-ce qui provoquait cette nécessité ? D'où venait l'agression ? Et sous quelle forme ? On a souvent affirmé que chaque milieu religieux, autant chrétien que musulman, imposait à l'autre les termes de sa démarche apologétique. Permettons-nous d'en douter. Nous venons de l'entrevoir, l'islam s'instituait, à la fin du VII' siècle, comme un monothéisme abrahamique, qui reposait sur une Écriture révélée et sur une histoire prophétique. Entre christianisme et islam, éclata donc un conflit des Écritures et des prophétologies. La stratégie de la littérature chrétienne fut celle de l'affirmation et de la négation, affirmation de la vraie foi et négation pure et simple de l'islam - le Coran n'a pas été révélé, Muhammad fut un faux prophète. L'apologie du christianisme comme vraie religion passait, en effet, par la négation obligée de l'islam, lequel se donnait à voir comme réalisation, accomplissement, du christianisme (ainsi que nous l'avons vu quant à la signification convenue du Dôme du Rocher). Autrement dit, dans la mesure où l'islam se construisait comme un enveloppement de la phase chrétienne de l'histoire de salut, et non par sa négation, c'étaient bien les termes islamiques de l'échange polémique qui s'imposaient aux lettrés chrétiens. Dans le différend des histoires de salut, les lettrés musulmans partaient, si l'on peut dire, avec l'avantage de ceux qui intégraient l'autre histoire - l'histoire de l'autre - et n'avaient pas à la nier.

Un autre défi devait être relevé par les lettrés chrétiens : répondre aux attaques vigoureuses des musulmans sur la Trinité et l'Incarnation, deux préceptes évidemment centraux et liés l'un à l'autre. On sait la violence avec laquelle les Arabes de la conquête et des générations qui suivirent ont réagi face à l'ostentation et à l'adoration de la Croix : l'idée même que Dieu fût incarné et qu'il fût crucifié leur était une abomination. Le déchaînement des destructions de croix fut grand, il fallait faire disparaitre l'image de l'impensable, mettre fin au trouble que cette image suscitait. L'Incarnation, avec ses fins que sont la crucifixion et la résurrection, était proprement objet d'exécration pour les premiers penseurs musulmans, pour lesquels l'idée que Dieu se fît homme et mourût de façon infamante était un 
reniement de toute transcendance. C'est à cette répulsion que dut répondre l'apologétique chrétienne. Mais encore une fois, c'est bien l'islam qui instaurait le débat, n'était l'action extrêmement offensive des musulmans contre les signes de l'Incarnation, l'urgence de l'apologétique n'eut certainement pas existé.

Ce qui ne veut pas dire que le christianisme n'a pas représenté un défi pour l'islam, défi d'une religion très majoritaire dans les pays conquis (jusqu'au $\mathrm{XI}^{\mathrm{e}} \mathrm{ou}$ $\mathrm{XII}^{\mathrm{e}}$ siècle au moins), fortement instituée, avec ses structures de pouvoir, etc. Mais la situation était très différente. C'est en se construisant, en établissant son capital dogmatique, en se donnant des institutions, en se forgeant une histoire prophétique que l'islam relevait le défi d'un christianisme omniprésent et redoutablement proche. Bien plus qu'en luttant pied à pied pour défendre ses prescriptions doctrinales. Pour les lettrés musulmans, le débat n'avait pas le même enjeu que pour leurs adversaires chrétiens. Ce qui ne veut pas dire non plus que le débat n'avait pas de nécessité pour ces lettrés musulmans, à l'évidence la controverse était une manière de préciser les frontières, car l'objet était "l'autre religion », ce qu'on lui déniait, ce par quoi l'on s'en distinguait. En un mot, l'islam n'avait pas à s'expliquer, alors que le christianisme se justifiait, s'expliquait longuement et laborieusement sur lui-même.

Les textes polémiques musulmans le montrent bien. Le projet de réfutation des autres croyances use de l'arme taxinomique, où les religions, hérésies, sectes, sont rangées selon leurs rapports à des catégories d'entendement (libre-arbitre ou prédestination, associationnisme ou monothéisme, transcendance ou immanence, etc.) plutôt que pour ce qu'elles sont elles-mêmes. Dans cette logique, tel groupement religieux recensé correspond parfois plus à une position à occuper dans un montage conceptuel qu'à l'occurrence effective d'un mouvement fait de fidèles, de rites et d'appareils. Les croyances décrites sont parfois abstraites, nominatives, renvoyant à des noms de fondateurs mystérieux, mais occupant une place précise dans un assemblage qui épuise le champ des possibles. C'est dans les milieux du rationalisme dogmatique, du mu'tazilisme, que ce travail de jalonnement des croyances et de constitution d'entours et de frontières à l'islam fut entrepris et mené à bien. Ces mêmes mu'tazilites s'occupaient plus précisément du christianisme - dans ses rapports aux mêmes catégories d'entendement - et engageaient la polémique contre les dogmes de la Trinité et de l'Incarnation. L'ouvrage du mu'tazilî Abû 'Alî al-Jubbâ'î (ob. 915 ou 916), Contre les chrétiens (Radd 'alā l-nasārā), est exemplaire de la méthode en usage.

David Thomas (2004) dit très justement que Abû 'Alî s'intéressait plus au fondement de la pensée chrétienne (de la Trinité, de l'Incarnation) qu'à la croyance chrétienne elle-même, c'est-à-dire à l'actualisation de cette pensée dans une pratique liturgique, institutionnelle. Mais cela s'explique par la procédure de ce rationalisme rigoureux. C'est à partir du dispositif conceptuel qu'il avait en usage que le Mu'tazili pensait, par exemple, la Trinité. Sa question était : est-ce que les trois figures de la Trinité sont trois attributs de Dieu, ou sont-elles ontologiquement autonomes? La réponse s'imposait: elles ne sont pas des attributs, mais les 
chrétiens disent que les trois figures de la Trinité sont un seul Dieu tout en étant distinctes. Aussi, ce qu'ils prétendent être des hypostases de Dieu sont en réalité des divinités séparées. La tentation du Mu'tazili était en conséquence de ranger le christianisme parmi les religions associationnistes. L'on comprend la procédure argumentative : c'est dans son écart à une catégorie islamique (l'attribut de Dieu) que l'objet «Trinité » est instruit ; puis vient une démonstration purement rationnelle (sur l'autonomie ontologique); le jugement ainsi obtenu qualifie le christianisme tout entier, et le range dans une classe doctrinale (associationniste) - aux côtés des polythéismes et des gnosticismes.

Quant à l'Incarnation, la démonstration de Abû 'Alî est du même ordre. Ici, le critère de démarcation n'est plus l'unicité de Dieu mais sa transcendance. La distinction infinie, irréfragable, entre le divin et l'humain n'existerait plus si Dieu était incarné : Jésus, en tant qu'homme, avait la posture de l'être adorant son Dieu, mais s'il était Dieu il s'adorerait ainsi lui-même. Ce qui est la négation formelle de la distinction conceptuelle entre l'humain et le divin, qui ne peuvent être associés en un seul être. Jésus n'a été qu'humain, et c'est en tant que tel qu'il a pu adorer Dieu. On ne peut guère reprocher (comme on a été tenté de le faire) à la posture du Mu'tazilî d'avoir ignoré tout - ou de s'être désintéressé - du mystère théologique chrétien, mais sa réflexion sur l'Incarnation était fondée sur la rationalité du maniement conceptuel (Watt, 2005), et, par voie de conséquence, intégrée dans une pragmatique de reconnaissance, dans le paysage monothéiste, des formes déviantes de croyance, dont la plus grave était la représentation de la transcendance par les traits de l'immanence, autrement dit la confusion, hors de la raison raisonnante, des concepts. En l'occurrence, le christianisme représentait pour lui cette gravité extrême, puisque Dieu incarné prenait tous les traits de l'homme. C'est pourquoi la remarque de David Thomas est très juste (2004 : 313), selon laquelle la démonstration des penseurs musulmans était tellement intégrée dans leur traitement conceptuel des faits religieux qu'il ne leur était pas nécessaire d'accorder un intérêt particulier aux manières pratiques dont ces faits étaient traités au sein du christianisme (en l'espèce, comme un mystère...).

Le célèbre débat entre le patriarche Timothée $1^{\mathrm{er}}(o b .823)$ et le calife AlMahdî (ob. 785) est très exemplaire d'une mise en scène commune (Troupeau, 2004 ; Thomas, 2005) : c'est (en théorie, nous y reviendrons) le questionnement musulman qui provoquait le discours chrétien. Le questionnement était : comment Dieu participe-t-il de l'Incarnation ? Comment une seule figure de la Trinité peut-elle être touchée par l'Incarnation ? Questionnement qui contraignait le débateur chrétien à réorienter sa pensée. En l'occurrence, il s'agissait pour Timothée (ou le Pseudo-Timothée, nous y reviendrons également) non pas de faire état du mystère mais de raviver une tradition théologique largement oubliée, qui avait consisté à travailler la possibilité de la coexistence du divin et de l'humain. Il s'était agi, en effet, d'un délicat débat d'époque patristique, qu'avait suscité le travail du paradoxe de l'Incarnation face au dogme de l'immutabilité divine, et de concevoir la possibilité de leur coexistence en instruisant la nécessité de 
l'absence de contamination, par le Fils, du péché de la chair. Mais, posée ainsi, la question ne changeait-elle pas de sens ? Si, par l'absence de péché, le Fils est distrait de l'humaine condition, est-il tout à fait homme ? En d'autres termes, le recours à cette ancienne tradition ne réduisait-elle pas le paradoxe à son minimum ? N'entamait-elle pas une vérité de croyance que la doctrine chrétienne voulait précisément paradoxale?

Au total, la controverse entre lettrés chrétiens et musulmans, et les littératures de la polémique et de l'apologie qu'elle engageait, ne se limitait pas à un conflit d'Écritures et de prophétologies, les conditions politiques de sa production touchaient un matériau doctrinal que les penseurs s'efforçaient de penser comme fixé, immuable, et auquel ils donnaient la forme de l'invariable. L'empire musulman dominait l'Orient chrétien, l'islam se représentait comme réalisé dans cet empire et réalisant une histoire humaine du salut qui intégrait, assimilait, le christianisme. La réponse chrétienne à cette prétention ne pouvait passer que par la négation de cette histoire, et donc de la croyance qui la supportait : le Coran était une forgerie humaine, Muhammad était un faux prophète. Les lettrés musulmans, parés de leur certitude de réalisation d'un monde de salut promis aux vrais croyants (à cet égard, l'enrichissement exponentiel de l'empire des premiers siècles était bel et bien considéré comme la réalisation de la promesse), n'avaient de cesse d'interroger le christianisme. D'un côté donc, il s'agissait de refuser la légitimité d'un mouvement religieux, malgré le constat inquiet de sa puissance, malgré la fascination qu'il opérait et que les Apocalypses dénonçaient à l'envi. D'un autre côté, il était urgent d'exhiber ce qui était en contradiction avec les axiomes d'une théologie qui se formalisait et qui, dans le travail de la distinction entre la vraie et la fausse voies, asseyait la domination politique de ceux qui suivaient la vraie voie. Le contexte dans lequel les écrits de controverse ont été diffusés participait centralement de leur sens. Et c'est en fonction de leur apparat contextuel, en quelque sorte, que leurs traits formels et leurs stratégies argumentatives peuvent être étudiés.

Reprenons un instant l'exemple du dialogue supposé entre Timothée $1^{\text {er }}$ et Al-Mahdî, à propos de l'Incarnation. Nous venons de le voir, la question oscillait entre celle des conditions de la coexistence entre l'humain et le divin et celle de la possibilité de cette coexistence. À cet égard, l'évolution rapide entre deux procédures argumentatives est instructive. Le chrétien 'Ammar al-Basrî (ob. vers 840) avançait en substance qu'en refusant l'Incarnation et la Trinité, l'islam privait Dieu de la plénitude de sa divinité. Son contemporain Théodore Abû Qurrâ (ob. vers 830) alla plus loin (Thomas : 2005). Son argumentaire ne se contenta pas de la négative, il se fit incisif, mais il nous intéresse surtout parce qu'il fut ensuite maintes fois repris, qu'il s'est largement imposé comme définitif. La nature humaine du Fils n'est pas une emprise sur le principe de manifestation de Dieu, elle ne le détermine pas : il n’y a aucune nécessité obligeant Dieu. En d'autres termes, il n'existe aucune contradiction entre l'Incarnation et le fait que 
Dieu est autrement existant, l'Incarnation ne porte pas atteinte à la divine puissance de Dieu, à son absolue transcendance. L'enveloppe humaine du Fils est une voie par laquelle les hommes peuvent appréhender Dieu. De même que Dieu, dit l'Écriture, est assis sur le trône : il n'y a aucune nécessité pour Dieu d'être assis, d'être en tel ou tel lieu - mais ainsi les hommes peuvent l'adorer. La forme de l'argument de Théodore est subtile, dans la mesure où il renvoie directement aux débats intra-musulmans sur, précisément, les représentations anthropomorphiques de Dieu (la main, l'œil, le trône, etc.), qu'elle fait écho aux querelles indécises des théologiens musulmans sur la question. Il reste que Théodore inaugurait, qu'il usait d'un nouvel argument : il n'y a pas de difficulté à penser l'Incarnation si celle-ci est comprise comme manifestation aux hommes. Au sens strictement théologique, Théodore faisait silence sur le lien essentiel établi entre l'Incarnation et la Résurrection, c'est-à-dire à l'Incarnation du Fils, qui conduit à sa mort et à sa résurrection, comme modèle d'une condition humaine qui chemine de la naissance à la mort et à la rédemption finale ( $c f$. Tertullien) ; de même qu'il faisait silence sur le caractère éminent de l'Incarnation, comme mystère central, nœud de tous les mystères, auquel se réfèrent et renvoient tous les mystères chrétiens ( $c f$. Origène). Enfin et surtout, Théodore se déplaçait délibérément sur le terrain de l'islam, il s'évertuait à faire comprendre l'Incarnation, à la présenter comme étant ni plus ni moins absconse que le trône ou la main de Dieu. Entré dans une telle logique discursive, il prenait le risque de déconnecter la manifestation du manifesté, l'Incarnation du principe divin. Répétons-le, la pensée de Théodore s'est largement répandue dans l'Orient chrétien, où elle a été comme un aboutissement, mais aussi un effacement.

Pour autant, d'autres lettrés chrétiens n'ont pas, comme Théodore, ressenti le besoin de rendre la croyance chrétienne lisible par les théologiens de l'islam, et s'ils sont allés sur le terrain musulman, nous le disions plus haut, c'était pour tenter d'en miner le fondement, tout au moins pour interroger la légitimité d'une construction dogmatique conséquente. Yahyâ ibn 'Adî en est un bel exemple (Platti, 2004 ; Baffioni, 2004). Logicien et théologien de Bagdad (ob. 974), parfait connaisseur de l'aristotélisme et de l'œuvre du musulman Al-Fârâbî (le "Second Maître ", 872-950), Yahyâ rédigea une réfutation de l'affirmation selon laquelle les actes "sont création (khalq) de Dieu et acquisition (kasb) de l'homme » (édition, Pines, 1996 ; voir Gimaret, 1980 ; Van Nispen Tot Sevenaer, 1996). Il est inutile de suivre ici les linéaments de l'argumentation de Yahyâ ibn 'Adî, mais il est important de prêter attention à sa stratégie.

Le traité de Yahyâ est un dialogue. L'interlocuteur musulman de Yahyâ avance ceci : Dieu a tout créé, c'est Lui qui a fait qu'un événement existe. Lorsqu'un acte est accompli par un ou des intermédiaires humains, alors le terme de l'acquisition s'applique à ce que l'acte implique. Si un homme a volé quelque chose, il mérite qu'on lui coupe la main : le fait qu'on lui coupe la main lui est acquis (est le $k a s b$ de son acte). Mais l'acquisition - poursuit en substance Yahyâ, tout en 
prêtant sa plume à l'interlocuteur musulman - n'existe que parce que celui qui agit «fait exister quelque chose qui est la cause de l'existence de ce qui, en soi, est lui-même acquis à celui qui agit ». Ainsi, l'acquisition est bien un acte de création, puisque "créer » et "faire exister» ne sont pas distincts. Or ceci est en contradiction frontale avec le fait que Dieu a tout créé. La conclusion de Yahyâ s'impose : son interlocuteur musulman se contredit. La lancinante question de la toute puissance divine et de l'autonomie de l'action humaine est au cœur de la théologie en régime monothéiste. Elle a tout autant préoccupé les milieux musulmans que les milieux chrétiens. Et les discussions, les interprétations et les propositions ont été nombreuses, notamment autour des thèses d'Al-Ash'arî (ob. 935), lequel avait précisément défini le premier le concept d'acquisition. Mais personne, ni Al-Ash'arî ni aucun autre lettré musulman, n'aurait jamais dit ce que Yahyâ faisait dire à son interlocuteur. Les propos de celui-ci ont comme prémisse le recouvrement entre créer (khalaqa) et agir ( $f a^{\prime}$ ala) : aucun musulman conséquent (et voué à la spéculation dogmatique, cela va sans dire...) n'aurait formulé pareille équation. La seule affirmation communément acceptée était que lorsqu'un acte (le fait d'agir) se produisait, il n'était pas le seul fait du pouvoir de l'homme. De fait, Yahyâ ibn 'Adî avançait masqué. Par souci de montrer que seule la thèse chrétienne sur la puissance de Dieu et l'autonomie de l'homme était pensable, il mettait en scène un interlocuteur imaginaire auquel il prêtait une non pensée, une aporie réflexive, et qu'il assimilait au commun des penseurs musulmans. En un mot, il tuait la controverse par la seule manière de l'exposer. Yahyâ n'avait pas le souci de rendre compte de la logique d'un interlocuteur qui fût véritable.

Nous l'avons vu, pas plus Yahyâ ibn 'Adî que Abû 'Alî Al-Jubbấî ne se préoccupaient de ce que croyaient vraiment leurs contradicteurs. Yahyâ et Abû 'Alî ne faisaient certes pas exception, dans un milieu où, qu'il fût chrétien ou musulman, il s'agissait simplement de montrer que l'autre (le contradicteur) pensait l'impensable, soit qu'il usât de prémisses fausses, soit qu'il usât de prémisses vraies mais dans un mauvais usage syllogistique. D'un côté et de l'autre les armes étaient les mêmes, comme la manière d'argumenter, comme - de façon plus globale - un certain savoir était partagé. Certes, leurs joutes polémiques étaient implacables, sans concession, mais lettrés chrétiens et musulmans du Proche et du Moyen Orient étaient socialement proches les uns des autres, leurs milieux n'étaient pas étanches. Tel lettré musulman avait un chrétien pour maître ou fidèle compagnon d'étude ; surtout, tel texte circulait largement et entrait dans un fonds culturel commun. On peut ainsi dire, pour conclure sur ce point, qu'un savoir partagé et que des formes réflexives semblables rapprochaient des hommes qui, par ailleurs, s'opposaient, opposaient leurs certitudes et leurs croyances religieuses.

Mais leurs différends ne relevaient pas que du domaine du pur idéel. La domination politique de l'islam et les lents mais sensibles mouvements de conversion 
religieuse et d'arabisation pesaient sur les stratégies argumentatives. Les textes polémiques chrétiens oscillaient entre le besoin de rendre lisible par les croyants musulmans une construction chrétienne de pensée, au risque de la dénaturer (Timothée, Théodore Abû Qurra) et celui de dénier à la croyance musulmane une nécessaire cohérence, au risque de manquer leur cible (Yahyâ ibn 'Adî). Les écrits musulmans, quant à eux, campaient sur l'affirmation satisfaite d'un monothéisme absolu et sur une démarche, quasi entomologique, de relevé de tout écart supposé, de toute déviance devinée (Abû 'Alî Al-Jubbâ‘̂i). Forts de leurs certitudes et de leurs croyances, ces polémistes se prenaient au jeu de la comparaison entre leurs religions, des comparaisons sur lesquelles, encore une fois, jouaient les pesanteurs du politique.

Comparaison veut dire attestation de supériorité, cela s'entend. Ce thème n'a guère été présent chez les théologiens et logiciens musulmans avant le tournant $\mathrm{du} \mathrm{XI}^{\mathrm{e}}$ siècle. Il a bel et bien été formulé, dès la fin du VII ${ }^{\mathrm{e}}$ siècle, avec notamment les inscriptions du Dôme du Rocher de Jérusalem et l'apparition de la littérature historiographique, mais (ainsi que nous l'avons noté) il en restait au constat que l'expansion de l'empire musulman constituait la preuve la plus ostensible de la réalisation présente d'une histoire prophétique de salut. Nul besoin, en somme, d'argumenter. Ce n'est qu'indirectement, et à l'extrême fin $\mathrm{du} \mathrm{X}^{\mathrm{e}}$ siècle que le thème de la supériorité de l'islam a été réellement formulé. Il s'agissait prioritairement de supériorité des hommes, plutôt que des croyances. Sous l'autorité d'Al-Fârâbî, l'on se mettait à considérer les Byzantins comme inférieurs aux musulmans, puisqu'ils avaient adopté le christianisme, religion de l'irrationnel, qui avait effacé toute trace de philosophie, nié tout ce que les anciens Grecs avaient enseigné. C'est sous cette forme, de prétérition, que le thème de la supériorité de l'islam - religion du déploiement de la raison - s'est répandu dans la littérature anti-chrétienne. Du côté chrétien, le travail a été beaucoup plus intense, et il a consisté en une sorte de déni du politique. Le thème est apparu très tôt, véhiculé notamment par le nestorien 'Ammâr al-Basrî, les jacobites Abû Râ'ita et Hunayn ibn Ishâq, le melkite Théodore Abû Qurra. Dans son Livre sur la façon de reconnaître la vérité d'une religion, Hunayn ibn Ishâq (ob. 873) précise que les croyants affirment tous la même chose : leur croyance leur vient d'une révélation ou d'une prophétie, ce qui prouve sa véracité. Mais la vraie religion, qui n'a pas eu besoin du véhicule de la guerre pour se propager, est celle que l'on adopte en dehors de la motivation immédiate d'accès à la richesse, à la rétribution, à la protection ou à l'émancipation (Landron : 71). À l'évidence, sans qu'il fût nommé, l'islam était ainsi désigné, un islam impérial, qui convertissait, qui attirait parce qu'il était puissant et facteur de promotion sociale.

La différence entre les deux manières d'aborder la hiérarchie entre les religions est frappante. Par les polémistes musulmans, ce n'est que secondairement que le christianisme était ainsi déconsidéré. Et bien injustement, faut-il le rappeler, hors de toute réalité. On sait bien que des chrétiens, comme le maître lui-même 
d'Al-Fârâbî, Yuhannâ ibn Haylân, ont transmis les écrits des anciens Grecs, que les héritiers de l'aristotélisme étaient autant chrétiens que musulmans, et que, encore une fois, les milieux " de la raison » étaient mêlés, faits de chrétiens et de musulmans qui se côtoyaient. Al-Fârâbî avait-il pensé un instant ce qu'on lui faisait dire ? Ses adversaires étaient plutôt les " hommes de la religion ", les théologiens du kalām (de la dogmatique), que ses pairs les logiciens chrétiens... À l'inverse, l'argument chrétien était ancré dans une inquiétante réalité, une réalité de la conversion à l'islam, de la fascination attestée - par les prédicateurs eux-mêmes (Décobert, 1992) - envers une religion triomphante. Paradoxalement, les écrits musulmans qui évoquaient la supériorité de l'islam s'abstenaient de relier directement celle-ci à sa réalité présente, d'une religion qui régnait, captait des âmes chrétiennes - comme si la réalité en elle-même suffisait. Mais les écrits chrétiens s'accrochaient à cette réalité, s'obstinaient à la décrire, pour précisément opposer une pure vérité à une vérité de plus en plus irréelle.

\section{La controverse en dialogue}

Les savants éditeurs et commentateurs des textes chrétiens d'apologétique et de controverse insistent beaucoup sur le caractère formel de certains d'entre eux, sur l'effet de réel que constitue leur forme dialogique ou épistolaire. Nous avons évoqué plus haut le traité de Yahyâ ibn 'Adî sur l'acquisition et l'interlocuteur musulman que Yahyâ introduit ; on connaît la célèbre correspondance entre le calife 'Umar ibn 'Abd al-'Azîz (717-720) et l'empereur byzantin Léon III (717741); mais d'autres échanges de lettres sont parvenus jusqu'à nous, tels entre l'astronome musulman Ibn Al-Munajjim et les logiciens chrétiens Hunayn ibn Ishâq et Qustâ ibn Lûqâ. La forme de dialogue direct semble avoir cependant été la plus fréquente. Les plus anciens textes connus datent du VIII siècle, ce sont notamment l'interrogation du patriarche Jean $I^{\text {er }}$ (patriarche syrien, de 631 à 648) par un émir musulman, la controverse du moine de Beth Hâlê avec un notable musulman, le récit épistolaire du patriarche Timothée $1^{\mathrm{er}}$, dans lequel il relate sa dispute avec le calife Al-Mahdî (le texte est ainsi la combinaison des deux genres).

On a rangé ces dialogues de controverse doctrinale en deux classes principales : le clerc dans l'assemblée du souverain ; le maître et le disciple (Griffith, 2005). Un tel classement appelle quelques remarques. Le scénario du dialogue entre le clerc et le souverain est simple : un clerc, généralement un moine, est convié à s'expliquer sur le christianisme dans un majlis (assemblée) de l'émir ou du calife. La mise en scène se voulait réaliste, situant le jeu des questions et des réponses dans un monde que connaissait le lecteur. Elle avait, d'autre part, une valeur kérigmatique, dans la mesure où le chrétien était défié, sommé de justifier sa croyance, par le souverain musulman : le chrétien devait être capable de défendre la croyance chrétienne. Mais une telle mise en acte situait la controverse, et la 
défense apologétique du christianisme, à l'intersection de deux champs : il s'agissait de relever le défi politique de l'islam - le souverain commande l'explication du clerc - par le discours d'exposé de la religion chrétienne - le clerc démontre la vérité du christianisme. Commandement d'un côté et démonstration de l'autre, double démonstration d'ailleurs, puisque la vérité du christianisme et la fausseté de l'islam sont à la fois signifiées. À cette fin, la composition du dialogue, c'està-dire l'enchaînement des arguments, allait de ce qui était partagé (entre chrétiens et musulmans) à ce qui était singulier (aux chrétiens). Et cette composition se figea très rapidement et se reproduisit, au long des générations et des siècles, pour former un corpus littéraire délibérément répétitif. Le clerc parle d'abord d'abrahamisme, puis il aborde l'histoire prophétique, pour enfin y situer Muhammad. Muhammad, constate le clerc, n'était pas envoyé à tous les hommes mais aux seuls Arabes, il n'était donc pas un prophète comme Abraham l'avait été. À partir de ce constat, c'est-à-dire du fait que l'islam s'est séparé du continuum abrahamique, l'héritage chrétien peut être décrit, à la fois dans son dogme (notamment la Trinité et l'Incarnation) et dans sa pratique (notamment la vénération de la Croix). Par là, ce dogme, au cœur des croyances du christianisme, s'inscrit dans la tradition abrahamique qu'il actualise. L'islam, puisqu'il est la religion d'un prophète qui a rompu la chaîne de prophétie abrahamique, n'a pas vocation à son universalité.

Très florissant $\mathrm{au} \mathrm{IX}^{\mathrm{e}}$ siècle, ce genre dialogique de controverse a produit de nombreux textes, les manuscrits aujourd'hui connus témoignent abondamment de ce phénomène. Les dialogues du maître et du disciple participent de ce corpus. Mais est-ce une classe distincte de celle que nous venons d'évoquer ? Au vrai, la joute entre le maître et le disciple est un jeu : le disciple "joue les musulmans » et c'est lui qui pose les questions, le maître "joue les chrétiens ", et il apporte les réponses. Le déroulement de l'argumentaire est rigoureusement le même que dans le débat entre le clerc et le souverain. Le caractère « théâtral » de cette joute introduit à un autre niveau de compréhension : le disciple fait en réalité son apprentissage par l'entremise de ce dialogue, le jeu consiste à lui faire prendre connaissance de ce qui doit être connu, doit être exprimé, doit être transmis de la doctrine chrétienne. Pour retourner l'assertion, disons que l'apprentissage - ou plus généralement : l'enseignement - prend la forme générique d'une joute. Mais n'est-ce pas toujours le cas ?

Reprenons les faits. On sait bien que la correspondance entre le calife 'Umar ibn 'Abd al-'Azîz et l'empereur Léon III n'est d'aucune réalité historique, il s'agit d'une construction littéraire. De même, quant au dialogue du patriarche Jean $1^{\text {er }}$, quant à la lettre de Timothée $1^{\text {er }}$ racontant sa dispute avec Al-Mahdî, etc. Tous ces textes, qui ont tant circulé, étaient des fictions littéraires. Mais qui dit fiction littéraire ne dit pas nécessairement absence de référent réel, vécu. La question est de savoir si ces entreprises de lettrés ont découlé de la réalité de disputes doctrinales qui ont effectivement eu lieu. Sidney Griffith pense que les débats 
interreligieux ont vraiment existé, qu'ils participaient d'une forme de culture partagée, dans l'Antiquité tardive et au Moyen Age, que d'ailleurs l'islam a promu. Il suffit de comparer ces débats à la pratique islamique de la dogmatique, le kalām, lequel serait la science même de la disputatio. Mais n'est-ce pas confondre forme et intention ? La forme dialogique de l'exposition d'idées est, à l'évidence, un fait de culture hellénistique, autant diffusé dans l'Orient musulman que dans l'Occident chrétien. Mais si l'islam en a hérité, il l'a nommé précisément " kalām », qui signifie « discours », c'est-à-dire non pas " parole échangée, contradictoire » mais clairement "parole d'exposition, de proposition ». Le kalām, en tant qu'il désignait la théologie dogmatique, et même, répétons-le, s’il prenait la forme du dialogue, n'avait pas pour intention d'opposer les arguments, encore moins de se situer sur le terrain de la dispute interreligieuse. Le kalām, comme rhétorique, était une méthode d'affirmation, d'enseignement.

Il est incontestable que des assemblées eurent lieu, on en cite à Bagdad, par exemple, pour le $\mathrm{XI}^{\mathrm{e}}$ siècle, assemblées au cours desquelles musulmans et non musulmans débattaient, argumentaient, confrontaient les affirmations et les dénégations. Mais ce que l'on en sait est instructif : la règle de ces assemblées était que l'on s'interdisait absolument d'opposer tel trait doctrinal à tel autre, telle citation scripturaire à telle autre, etc. Seuls les principes de la raison raisonnante et de l'argumentation syllogistique étaient admis. Ces assemblées étaient, en fait, des rencontres de logiciens et de rhétoriciens, et elles étaient, faut-il insister, très mal vues des autorités religieuses. Sidney Griffith cite à ce propos un bel exemple (qui contreviendrait plutôt à son hypothèse...), selon lequel un homme, aux fermes convictions musulmanes, relate avoir été invité à assister à l'une de ces assemblées et avoir exprimé sa profonde réprobation à l'idée que de telles assemblées pussent exister (2005: 121-123). Pour notre propos, ces discussions ouvertes de logiciens et de savants ne pouvaient servir de référents probants, loin s'en faut, prouvant l'existence de débats tels que la littérature apologétique et de controverse les a consignés. Car cette littérature fonctionnait précisément sur d'autres règles, où l'Écriture s'opposait à l'Écriture, le trait dogmatique au trait dogmatique, où la doctrine chrétienne était présentée pour elle-même et, inversée, dans la forme improbable de la doctrine musulmane. C'est-à-dire loin de la rigoureuse démonstration syllogistique, héritée de la philosophie aristotélicienne. Au total, il convient certainement de dire que l'apologétique chrétienne, sous sa forme dialogique, a été pour des siècles un véhicule d'enseignement, d'exposition des croyances, bien plus que de vraie controverse. Les lecteurs et auditeurs visés étaient chrétiens, de tels textes n'étaient pas écrits à l'intention première des lettrés musulmans.

Un dernier exemple permettra peut-être de préciser les choses. Il s'agit de la légende du moine Bahîrâ. On a pu être tenté de la ranger dans la classe de la controverse dialogique (Griffith, 2005), mais il s'agit exactement du contraire. Dialogue, certes, mais non controverse : elle est de pure apologétique. Cette 
histoire, extrêmement populaire dès le début de l'époque abbasside, relate la rencontre, aux confins de la Syrie, entre le moine Bahîrâ et le jeune Muhammad, alors jeune homme attaché à une lourde caravane venue d'Arabie, bien avant qu'il ne devînt le messager de Dieu. La version musulmane de la rencontre a été consignée dans la Sîra nabawiyya de Muhammad Ibn Ishâq (ob. 768 ; voir Guillaume, 1955 : 79-81). Cette biographie canonique du Prophète de l'islam raconte simplement que Bahîrâ reconnut, en Muhammad, le prochain prophète, celui qui scellerait l'âge de la prophétie, et il conseilla aux aînés de la caravane de bien protéger ce jeune élu de Dieu. Dans les versions chrétiennes, par un jeu de questionnements et d'enseignements, Bahîrâ dévoile à Muhammad ce qui « sera bon » pour l'islam, et qui est évidemment d'essence chrétienne. Corollairement, le lecteur comprend que ce qui ne sera pas bon pour l'islam ne consistera qu'en corruption, déformation, dévoiement du sens du message chrétien. Si la forme du débat est le support à l'expression de vérités religieuses, et si donc la légende de Bahîrâ se rapproche de la forme littéraire qu'est la dispute entre le clerc chrétien et le gouvernant musulman, ce n'est précisément pas parce que ces vérités religieuses sont réellement discutées mais bien parce qu'elles ne sont qu'imposées. L'intérêt de la légende de Bahîrâ est qu'elle montre comment le moine façonne le futur prophète, l'instruisant, lui révélant - avant la révélation ce qui est vrai, ce qui est saint. En somme, le dialogue s'épuise dans la pure exposition de la vérité et le moine, véritable initiateur de vérité, est le double du maître, qui instruit le disciple « jouant les musulmans », autrement dit représentant ceux qui ne connaissent pas la vérité. De façon aveuglante, la parabole de Bahîrâ montre à quel point le dialogue n'en est pas un. Mais l'important, en définitive, est peut-être que l'exposition de la vérité ait pris la forme singulière d'une assignation à comparaître et à dire cette vérité, d'un acte d'assignation dont l'acteur était le régnant arabe, l'homme de la domination politique.

On peut regretter que les études de synthèse sur la polémique islamo-chrétienne n'aient pas souvent considéré le champ de la longue durée, et que la plupart d'entre elles se soient consacrées aux périodes hautes, des premiers siècles de l'islam. Or l'étude de l'inscription de ces textes dans une histoire longue (qui fut notamment celle d'une islamisation massive), permet de percevoir mieux encore comment, dans leurs formes, leurs propos, leurs modes d'exposition, ils ont été touchés par « ce qui se passait ». Nous nous sommes attardés sur le constat de cette emprise, sur une domination politique et économique qui se faisait religieuse, au point que les vérités de croyance (l'Incarnation...) étaient travaillées en fonction d'une conceptualisation islamique qui se diffusait largement, se révélait contaminante ; et symbolique, au point que la figure du gouvernant musulman faisait intrusion comme suscitant la production même de ces discours. Mais l'histoire longue des chrétiens en Orient a été de plus en plus celle de la conversion de bon nombre d'entre eux, de la paupérisation des communautés restantes, de l'islamisation des paysages. Ce décor, qui n'était plus seulement de domination, 
de contamination, mais aussi de désarticulation sociale, travaillait les textes de polémique religieuse. La récente édition (et traduction) de la Lettre des gens de Chypre permet de saisir l'effet d'une telle contrainte contextuelle tant sur la forme que sur le fond des textes d'apologétique chrétienne (Ebied \& Thomas, 2005).

En 1321, une Lettre des chrétiens de Chypre fut envoyée au savant musulman Ibn Abî Tâlib Al-Dimashqî, lequel rédigea une réponse. Cette Lettre et l'échange polémique qu'elle provoque ont une histoire, il faut s'y arrêter. L'origine de ce texte est une Lettre à un ami musulman, rédigé par Paul d'Antioche. Nous ne savons rien sur cet évêque melkite, qui vécut certainement au tournant du XIII ${ }^{\mathrm{e}}$ siècle. Paul dit avoir voyagé dans l'Occident chrétien et avoir consulté nombre de savants à propos de l'islam. Ceux-ci, Coran en main, y ont puisé toutes les raisons qui les empêcheraient d'être attirés par l'islam, et, qui plus est, toutes les raisons qui pousseraient les musulmans à abandonner leur religion. En effet, selon ces prétendus savants, le Coran reconnaît les dogmes chrétiens, à propos du Christ particulièrement, de la Trinité ou de l'Incarnation, et montre bien que Muhammad n'était qu'un prophète pour les Arabes. Ainsi, le texte coranique a cette double caractéristique de ne pas concerner les chrétiens (il est le message prophétique adressé aux Arabes) mais de reconnaître la vérité de leur croyance. À l'appui de ses affirmations, la Lettre de Paul cite largement le Coran, néanmoins soit la mention coranique est controuvée et les mots en sont changés pour correspondre à la démonstration en cours, soit la citation coranique est juste mais ne dit pas ce que le commentaire lui fait dire. Le succès de la Lettre de Paul, dans les milieux chrétiens d'Orient, fut grand. Elle était à l'évidence l'œuvre du seul Paul d'Antioche, le voyage d'Occident et la consultation d'experts n'y sont qu'un artifice littéraire, et la doctrine chalcédonienne y est clairement signifiée.

Elle a également été connue des savants musulmans ; Ibn Taymiyya, notamment, l'évoquait comme une source première d'autorité parmi les chrétiens de son temps. Mais nous ne pourrions affirmer qu'elle était, comme son titre l'invite, destinée à des lecteurs musulmans. L'argument de la Lettre est que Muhammad fut un prophète local. Non pas un faux prophète, comme les plus anciens écrits polémiques l'avaient affirmé ( $c f$. supra), mais un prophète pour les Arabes seulement. Le changement dans le jugement est notable. L'islam n'était plus désormais une religion qu'il fallait nier, et par conséquent réfuter radicalement. Le réalisme s'imposait certainement : la réfutation n'aurait eu guère de sens, d'une religion qui s'était fermement instituée, et dont l'expansion était si continue et si visible. La présence de l'islam imposait qu'on l'intégrât finalement dans le plan de Dieu, dans une histoire de salut, en l'occurrence une histoire de la rédemption. Dire ainsi que Muhammad était un prophète pour les Arabes revenait certes à l'intégrer dans la classe des prophètes de Dieu, mais signifiait surtout que l'islam était, en somme une propédeutique. Une voie pour les Arabes, peuple païen, vers le christianisme. C'est pourquoi l'écriture coranique annonce le christianisme, c'està-dire l'établit comme doctrine et comme devenir. De la sorte, la Lettre de Paul 
réorganisait le temps de la prophétie, qui filait du paganisme à l'islam et enfin au christianisme. L'islam se réalisait dans le christianisme, après qu'il s'instaurait comme une religion de la sortie du paganisme. Il s'agissait d'une formidable réplique à l'ancien discours islamique de l'islam comme réalisant le christianisme (cf. supra). Mais les circonstances - sociales, historiques - étaient très différentes. Reprenons notre question : la Lettre était-elle destinée à des lecteurs musulmans ? Si oui, elle aurait largement raté sa cible. Aucun musulman connaissant quelque peu le Coran n'aurait accepté ces fausses citations et ces commentaires trompant le sens du Coran : elle serait apparue comme une grave provocation. Ce n'est évidemment que par accident, et parce qu'elle circulait largement, que la Lettre tomba entre les mains de quelques savants musulmans qui, tel Shihâb al-Dîn Al-Qarafî, se sont empressés d'y répondre avec humeur ou qui, tel Ibn Taymiyya, l'ont prise comme une preuve de dévoiement du christianisme.

Plus normalement, nous devons considérer qu'elle était destinée à des lecteurs chrétiens, dans une intention précise : faire accepter l'islam par les chrétiens. L'islam était là, la nécessité était de le considérer pour ce qu'il était, un régime de croyances et d'institutions, et de lui accorder une place dans l'économie du salut. Au total, sur la durée de quelques siècles, l'écart était grand : dès qu'il fut apparu, l'islam se présenta à lui-même comme la fin du christianisme, comme son achèvement, comme le sceau de la voie prophétique et le retour final à cette vraie voie ; un christianisme d'Orient, concédait pour lui-même et tardivement à l'islam une place dans la prophétie d'essence abrahamique. Mais ce faisant, en un temps où l'islam, par voie de conversion, devenait majoritaire en Orient et où les communautés chrétiennes étaient réduites à des îlots dans un œkoumène islamisé, la Lettre à un ami musulman émettait un message clair à des chrétiens que la religion dominante assurément tentait : l'islam existe, certes, et il est la voie des Arabes vers le salut, mais l'islam n'existe que pour les Arabes, il ne fut prêché qu'aux Arabes, il serait diabolique pour un chrétien de se laisser séduire par une religion qui lui est étrangère... L'ethnicisation de l'islam se faisait désormais au prix de sa reconnaissance.

Au début du XIV siècle, la Lettre à un ami musulman fut réécrite. Sous une forme modifiée, connue désormais comme Lettre des chrétiens de Chypre, elle fut envoyée en 1316 à Ibn Taymiyya et sous une forme encore un peu différente, en 1321, à Ibn Abî Tâlib Al-Dimashqî (Ebied \& Thomas, 2005 : 54-147). Les éditeurs et traducteurs de cette dernière lettre ont établi un excellent inventaire de toutes les modifications que l'auteur anonyme a apportées à la Lettre de Paul d'Antioche. Retenons pour l'essentiel que le nouveau rédacteur a cru bon de livrer des citations coraniques exactes, au risque évident d'affaiblir le commentaire qu'il reprenait de Paul d'Antioche ; qu'il évoquait la figure de Jésus en supprimant les passages qui, dans la Lettre de Paul, avait explicitement mentionné les chrétiens comme ceux qui, exclusivement, suivaient son enseignement ; qu'il multipliait, bien plus que Paul ne l'avait fait, les citations bibliques relatives aux prophètes 
de l'Ancien Testament, dans le but de montrer que le Coran entérinait cette histoire prophétique et $d o n c$ sanctionnait l'autorité de la Bible, se soumettait à sa vérité. Les éditeurs soulignent justement que la Lettre des chrétiens de Chypre s'évertuait à gommer tout ce qui marquait ostensiblement l'appartenance religieuse de son auteur, comme si une neutralité était souhaitée, entre les deux religions.

Il est difficile de penser qu'une vraie neutralité était recherchée par cet auteur anonyme qui, s'affirmait chrétien, mais connaissait certes intimement le Coran et la pensée commune des musulmans. Les savantes modifications du rédacteur anonyme (lequel, parfait arabophone, ne devait pas être chypriote...) avaient un objectif : rendre la Lettre acceptable pour un lecteur musulman. D'ailleurs, la Lettre a été intentionnellement attribuée à Ibn Abî Tâlib Al-Dimashqî, déposée à son domicile de Damas. Le message restait le même que celui de la Lettre à un ami musulman, n'étaient les faiblesses argumentaires dont il faisait preuve, puisqu'il s'interdisait de puiser dans un Coran contrefait les preuves de ce qu'il avançait : le christianisme est l'avenir de l'islam. Mais changeant de destinataire, un même message changeait de sens - car l'information qu'émet un tel message rend compte, aussi bien que d'une pensée brute, de la situation de celui à l'intention de qui il est émis. S'il est expliqué à un musulman que Muhammad a été un prophète pour les Arabes, et non pas pour tout le genre humain, s'il lui est dit également que Jésus, reconnu par l'islam, fut à l'origine et au fondement du christianisme, il est dès lors signifié à ce musulman qu'il se doit de considérer le christianisme au moins à l'égal de l'islam. En l'occurrence, qu'il ne peut s'engager dans une procédure de persécution d'une religion que Dieu a voulue, que Jésus a générée. Car le temps - début de l'ère mamelouke - n'était pas seulement à la conversion à l'islam, à la perte des âmes chrétiennes, il était, au Proche-Orient et en Égypte, à une forte campagne de déstabilisation des communautés chrétiennes. Depuis la fin du XIII siècle, des sermons et opuscules, rédigés par des juristes ou des soufis (voir notamment Belin, 1851; Gottheil, 1921 ; Perlmann, 1940-42 ; Gril, 1980 ; Catlos, 1996 ; El-Leithy, 2005), dénonçaient l'arrogance des chrétiens, exigeaient le retour à la stricte gouvernance de la dhimma, s'en prenaient aux notables chrétiens dont l'administration musulmane s'attachait les services, s'attaquaient enfin aux nouveaux convertis qui, musulmans de façade, n'étaient jamais que des crypto-chrétiens... Un tel mouvement, dont il faut chercher les motivations dans une identification très neuve et très bouleversante de l'homo islamicus, identification que le soufisme confrérique promouvait et diffusait alors très largement dans les pays de domination musulmane : la croyance intime comme seul gage de l'identité religieuse. Les chrétiens du Proche-Orient et d'Égypte ne furent pas les premières cibles, loin s'en faut, de la politique de mise en conformité de l'identité intime et de l'appartenance communautaire, les procès d'une véritable inquisition frappèrent d'apostasie nombre de musulmans. Mais ils furent persécutés parce que la simple logique de mise en conformité entre l'intimité et l'appartenance redessinait les frontières communautaires, durcissait 
les distinctions, et tendait à expurger l'œkoumène musulman de ces « entre-deux ", de ces zones de groupements indécis, de proximité entre des hommes de croyances différentes, de ces réseaux d'interactions au quotidien, de ces ententes et collusions. Les communautés chrétiennes, et surtout leurs élites, qui précisément s'étaient nourries depuis déjà quelques siècles à ces "entre deux ", qui y avaient puisé une bonne part de leur plasticité, de leur capacité à se reproduire, s'en trouvaient brutalement affaiblies.

Ce n'est assurément pas un hasard si la Lettre des chrétiens de Chypre, une missive si "présentable », est parvenue à un juriste connu pour son rigorisme doctrinal et son appétit pour la lutte pamphlétaire, Ibn Taymiyya, ce n'est pas un hasard si elle a été déposée chez un homme de poésie et de grande érudition, Al-Dimashqî. C'est peut-être que - quitte à renoncer partiellement aux armes de la polémique - l'espoir du savant anonyme, qui patiemment avait procédé à un travail de réécriture, de gommage, était de voir dans une relation de dialogue entre des hommes du savoir, d'un dialogue véritable et non pas seulement de fiction littéraire, un gage de survie pour sa communauté. Pourquoi donc les éditeurs de la Lettre sont-ils allés chercher dans l'histoire des dernières croisades ce qui participait du quotidien même des chrétiens d'Orient ?

\section{Martyre et histoire}

L'une des formes paradoxales d'historiographie chrétienne médiévale a été l'hagiographie et en particulier ce qu'on pourrait appeler la néo-martyrologie. À propos de néo-martyrs, de martyrs chrétiens d'époque arabe, de véritables notices historiques ont été rédigées, qui faisaient relativement peu de cas du merveilleux (miracles, apparitions, etc.), mais qui dessinaient des décors sociaux d'un fort réalisme, relataient des faits historiquement vraisemblables voire vrais, évoquaient les noms des régnants, les dates, les lieux... En un mot, ces notices martyrologiques sont apparues comme d'indiscutables chroniques, informant les spécialistes tout aussi bien que les Annales ou les grandes fresques historiques. Mais l'important est que les martyrs, en tant qu'ils sont reconnus comme tels, sont censés porter en eux, les vertus cardinales de leur peuple (Albert, 2001). Dans le sacrifice de leur mort, c'est-à-dire dans un engagement total et dans l'oubli de soi, les martyrs ne sont plus que des expressions de valeurs partagées.

Parmi les récits de martyre d'époque médiévale, celui de Jean de Phanidjôit est très singulier dans l'hagiographie chrétienne d'Orient. Mort en martyr au Caire en l'an 1209, mais totalement inconnu de l'Église copte (il n'existait rien sur lui dans les Synaxaires, les calendriers coptes des saints), il a néanmoins été l'objet d'un long récit biographique, lequel est resté, oublié, dans les archives du monastère de Saint-Macaire, en Basse-Égypte. Ce texte, exhumé par Gabriel Tukhy et édité par Émile Amélineau, à la fin du XIX ${ }^{\mathrm{e}}$ siècle, retomba dans un nouvel oubli, mais il ressuscite enfin grâce à quelques savants travaux (MacCoull, 
2000 ; Décobert, 2005 ; Zaborowski, 2005). Et un mouvement de fidèles coptes - au demeurant fort puissants, installés sur la côte ouest des États-Unis - a récemment proposé, et obtenu du patriarcat, son inscription au Synaxaire...

L'étude de Jason Zaborowski est aujourd'hui la plus complète sur ce mystérieux Jean de Phanidjôit et il faut d'emblée la saluer pour sa précision, la qualité de l'édition et de la traduction du texte qui en constitue le matériau, mais aussi pour l'ampleur de son analyse historienne. Mais rappelons brièvement l'histoire supposée de ce néo-martyr. Jean est né, à la fin du $\mathrm{XII}^{\mathrm{e}}$ siècle, dans le village chrétien de Zaytûn, en Moyenne-Égypte. Zaytūn, en arabe, veut dire « olivier "; en copte, le mot phanidjôit veut également dire "olivier ", et puisque le texte dont nous parlons a été écrit en copte (nous en reparlerons), Jean est dit "Jean de Phanidjôit ». À l'âge adulte, Jean quitte son village et se convertit à l'islam. L'explication de sa conversion paraît claire : Jean tenait commerce de draperies, son activité le faisait fréquenter des musulmans, et peu à peu, se rapprochant d'eux, il a fini par succomber, par passer à l'islam et épouser une musulmane dont il a deux fils. Mais le remords le prend et Jean veut redevenir chrétien. Il apprend que l'administrateur de la contrée de Biblaw (un peu plus au sud, en Moyenne-Égypte) n'est pas hostile aux chrétiens et surtout qu'il laisse en paix ceux qui, chrétiens convertis à l'islam, sont revenus secrètement à leur religion première. Jean se rend donc à Biblaw et y vit quelque temps. Mais le remords ne cesse de le hanter, et il comprend qu'il n'en sera délivré que s'il redevient formellement chrétien et qu'il abjure l'islam. Jean se décide enfin à se rendre au Caire et à attirer sur lui l'attention du sultan ayyoubide Al-Malik Al-Kâmil (qui règne alors sur l'Égypte pour le compte de son frère, Al-Malik al-'Adil), n'écoutant pas les conseils de ceux qui tentent de le distraire de cette volonté insensée. Après avoir provoqué le cortège du gouverneur du Caire un jour de procession, Jean est emprisonné à la Citadelle. Le sultan Al-Malik Al-Kâmil le fait sortir de sa geôle et l'entend publiquement. Jean lui fait part de sa volonté : fais que je redevienne chrétien; à laquelle le sultan n'a pour réponse que le droit : tu connais la loi, tu es musulman, en devenant chrétien tu serais apostat, donc puni de mort... De retour dans sa cellule, Jean reste inébranlable. Le sultan, se refusant à verser le sang, use de la menace et de la persuasion pour le faire changer d'avis ; il lui envoie son médecin, le chrétien Abû Shâkir, qui n'a de cesse de lui signifier que c'est toute la communauté chrétienne que Jean embarrasse à s'obstiner ainsi et à provoquer le sultan. Rien n'y fait, Jean ne faiblit pas. Jean de Phanidjôit est finalement décapité le 4 pachôn 925 de l'ère des Martyrs (29 avril 1209), son corps est jeté dans le Nil, pour que nul ne recueille ses reliques et ne les vénèrent.

Ce beau et long récit est connu par un manuscrit copte unique, il occupe les folios 40r à 55v du Cod. Vatic. Copt. 69. Il aurait été rédigé, dit le texte, à l'approche du premier anniversaire de la mort de Jean de Phanidjôit, soit en 1210, ce qui lui donne sa forme d'encomium. C'est en 1715 que le Codex est arrivé à Rome, à la Vaticane, dans un lot que le collectionneur et chasseur de manuscrits Joseph Simeonis Assemani a ramené du monastère de Saint-Macaire. 
Mais le mauvais état du Codex a incité Raphaël Tukhy, traducteur et copiste à la Vaticane, à le recopier. À la fin du XIX siècle, le grand défricheur de l'histoire chrétienne de l'Égypte, Émile Amélineau, redécouvrit le manuscrit, il l'édita et le traduisit en 1887 sur la copie de Tukhy. Mais celle-ci était fautive et le manuscrit original fut enfin publié : après une édition scientifique (Balestri \& Hyvernat, 1924), une traduction latine parut enfin (Hyvernat, 1950).

Logiquement, l'étude de Jason Zaborowski repose sur l'idée que ce texte est un exemple particulièrement éclairant du processus d'assimilation des coptes à une société sous domination musulmane. Mais elle veut également répondre à la question de savoir pourquoi le texte fut rédigé en copte, alors que, de toute évidence, le copte n'était plus en usage en Égypte. L'argument de l'auteur est le suivant: les chrétiens d'Égypte, sous les Ayyoubides, étaient en situation de grande vulnérabilité, ce qui leur faisait perdre leurs repères et les amenait à s'assimiler, à se fondre, sans autre distinction que leur culte, dans une société où l'islam était partout prégnant. Ainsi, le martyre de Jean de Phanidjôit doit être vu comme une réaction à ce qui doit être considéré comme une crise d'identité. À cette fin, le récit du martyre s'efforce de placer au niveau de l'éthique l'enjeu d'une telle assimilation. Celle-ci y et représentée comme une pollution. L'interaction avec les musulmans y est décrite comme contaminante, polluante; et le refus de l'assimilation - c'est-à-dire l'affirmation de la différence chrétienne - est signifié comme une véritable préservation. L'attirance des chrétiens dominés envers une société musulmane dominante n'est vue que comme une coupable séduction pour la souillure...

La stratégie qui règle la narration du martyre de Jean de Phanidjôit consiste ainsi à fonder la distinction entre chrétiens et musulmans sur des discriminants non pas tant religieux qu'ethniques. Les gouvernants de l'Égypte ne sont pas tant des croyants de l'islam qu'un ethnos, intrinsèquement attaché à son immoralité, à son impudeur, à son avidité pour les biens de ce monde. La motivation profonde du martyre de Jean de Phanidjôit est, en conséquence, d'exposer publiquement l'indignité de régnants qui n'ont imposé que la souveraineté du mal sur l'Égypte. Et le sens du débat entre le martyr et le sultan - débat dont Jean de Phanidjôit sort vainqueur, puisque resté fidèle à sa volonté - est à voir comme une appropriation et une inversion des traits de l'idéologie dominante, que le pouvoir ayyoubide impose à tous. Contre ce mal imposé, la parole du martyre sera celle du bien, de la vraie foi et de l'innocence recouvrée. C'est pourquoi Jean de Phanidjôit a cru pouvoir provoquer le sultan Al-Malik al-Kâmil et lui demander le rachat de son identité chrétienne. C'est pourquoi ce qui est considéré par l'islam comme une apostasie (renier l'islam pour devenir chrétien) n'est considéré par le médecin Abû Shâkir que comme un simple mensonge. L'action du converti repentant et la décision du médecin rendent au martyr Jean de Phanidjôit la maîtrise de son destin, la reconnaissance de ses repères, c'est-à-dire de sa vérité de croyance, indépendamment de tout dispositif musulman d'imposition. 
Mais un tel propos, explique Jason Zaborowski, aurait été suicidaire s'il avait été émis en arabe, c'est-à-dire s'il avait pu être lu par les musulmans. Là est la raison pour laquelle la langue copte a été celle de la présente narration. D'où le recours du savant coptisant à ce que les historiens des dominations religieuses ou politiques appellent l'usage du hidden transcript, c'est-à-dire de la langue des dominés dans leurs écrits, quand celle-ci est inconnue des dominants, ou tout au moins d'un mode crypté de communication. En ce sens, Jason Zaborowski s'oppose résolument à l'idée qu'avait émise, il y a bien longtemps, Paul Casanova (Casanova, 1901), selon laquelle les incongruités linguistiques du texte copte s'expliquaient tout simplement par le fait qu'il avait été traduit d'un original arabe. Idée évidemment insupportable, qui, si elle était avérée, ruinerait la savante démonstration. Aussi, en analyse d'une belle édition scientifique et une traduction anglaise du texte d'une grande précision, Jason Zaborowski s'emploie (chap. 3) à banaliser les fautes et les approximations de langue et à nous convaincre qu'en définitive les questions non résolues sur les occurrences de termes obscurs et sur les hapax sont beaucoup plus dues à notre ignorance de la langue copte de cette époque qu'aux ignorances du texte lui-même (p. 135). Mais suffit-il de penser à un scribe fatigué ou malhabile plutôt qu'à un scribe qui traduit, et parfois translittère de l'arabe des mots qui n'ont pas en copte leurs équivalents... ?

Le dernier point de l'étude de Jason Zaborowski (chap. 4) consiste à élargir le champ d'analyse et à replacer le cas Jean de Phanidjôit dans le règne ayyoubide, inauguré par Saladin, et des Croisades. Sur les indices que lui fournit l'Histoire des patriarches d'Alexandrie (Khater \& Khs-Burmester, 1970) l'auteur avance en substance ce qui suit. La politique des Croisés fut de tenter d'unir à eux les chrétiens d'Orient, tant les monophysites d'Égypte que les chalcédoniens de Syrie. Pour la contrer, l'attitude de Saladin fut de mener en même temps l'offensive de la guerre et le jeu de la diplomatie. Il comprit qu'il lui fallait à la fois combattre les Croisés et se rendre " aimable » envers les coptes et donc briser le front chrétien en Orient. Mais pris dans la lutte entre Croisés et Ayyoubides et sous la férule du génial Saladin, les coptes vivaient un double danger : soit ils étaient identifiés aux chalcédoniens (en tant que chrétiens, indistinctement, qu'ils fussent monophysites ou diphysites) soit ils étaient associés aux musulmans (en tant qu'Orientaux, indistinctement). Dans les deux cas, la perte d'identité propre des coptes d'Égypte était certaine. Tel serait le contexte dans lequel le martyre de Jean de Phanidjôit a été produit. Face à ce double danger, le martyre propose précisément une double réponse, qui est de sauvegarde identitaire : l'affirmation doctrinale, qui éloigne du chalcédonisme (c'est-à-dire d'un christianisme oriental non monophysite), le refus de l'interaction avec les musulmans, qui éloigne de l'islam (c'est-à-dire de la religion dominante).

La thèse avancée par Jason Zaborowski est séduisante, elle est fermement argumentée et il y a lieu de croire qu'elle convaincra plus d'un spécialiste des "études chrétiennes ». Nous tenons cependant à en discuter certains points essentiels, ne 
serait-ce que pour prolonger le passionnant débat qu'il a engagé. Remontons la chaîne de ses arguments.

Nous devons, en premier lieu, douter de l'Histoire des patriarches d'Alexandrie. Il n'est pas exact que ses propos aient été un reflet fidèle de la politique de Saladin envers les chrétiens. Ou plutôt convient-il de signaler (Martin, 1985 : 29-30) que l'Histoire des patriarches est devenue, depuis le début du XII siècle, un simple décalque des chroniques musulmanes qui, comme celles-ci, consigne, année après année, les principaux événements survenus, qu'ils soient relatifs aux crues du Nil, aux tremblements de terre, aux prix des céréales, aux soubresauts au sein de la dynastie régnante, aux changements dans l'administration centrale, aux campagnes guerrières contre les Croisés, etc. Quant à l'histoire proprement chrétienne d'Égypte, en particulier celle des patriarches dont elle était l'objet, elle est quasiment absente : on n'y apprend presque plus rien de ce qui a pu réellement s'y passer. Quelques indications permettent de repérer l'élection d'un patriarche, la date de sa mort. De brefs récits de dimension communautaire sont consignés, mais ils ne sont plus, comme ils avaient pu l'être auparavant, les prétextes à de longs commentaires : la conversion de tel juif au christianisme, le passage à l'islam de tel moine qui se prend à persécuter ses anciens frères, le martyre de tel apostat (c'est-à-dire, comme Jean de Phanidjôit, de tel chrétien converti et voulant revenir au christianisme).

Pour revenir à notre propos, l'Histoire des patriarches ne rend pas compte de la politique de Saladin et de ses successeurs ayyoubides envers les chrétiens; elle n'en dit quasiment rien et ce qu'elle en dit ne correspond pas à une réalité que l'on connaît bien par ailleurs. En quelques mots, précisons que Saladin n'a pas été tendre avec les chrétiens, notamment d'Égypte. Sa prise de pouvoir au Caire (en 1170) a été suivie d'une série de mesures restrictives envers les gens du Livre, chrétiens et juifs, des mesures qui rétablissaient un ordre religieux que garantissaient la stricte observance de la Sunna (la tradition prophétique). Il est important de considérer que la restauration sunnite, dont Saladin a été l'artisan efficace après la chute du califat chiite des Fatimides, a eu pour corollaire la volonté de réaffirmer les règles de la dhimma (discrimination et protection des gens du Livre), puisque l'on reprochait aux Fatimides d'avoir favorisé les chrétiens et les juifs... D'autre part, il apparaît que la crainte d'une certaine alliance entre chrétiens d'Orient et Croisés est postérieure aux événements qui nous concernent ici (le martyre de Jean de Phanidjôit aurait eu lieu en 1209). Ce n'est que dans les années 1219-1220, durant la cinquième croisade, que le sultan ayyoubide Al-Malik al-Kâmil put croire en une alliance entre les nestoriens d'Alexandrie et les Croisés (après la prise de Damiette, en 1217) ; une alliance dont la matérialité a d'ailleurs été largement contestée, relevant plutôt d'une propagande latine que d'une réalité locale (Al-Makîn ibn al-'Amîd, 1994 : 26-30 ; Sivan, 1967 ; Richard, 1996 : 310-318). Les croisades et l'appréhension ayyoubide d'une alliance entre chrétiens ne pouvaient être à l'arrière-plan politique du martyre de Jean. 
Il convient plutôt de signaler que l'Histoire des patriarches, comme toute l'historiographie chrétienne (Griffith, 2004 ; Harrak, 2005 ; Morony, 2005 ; Thomson, 2005 ; Van Ginkel, 2005), était une chronique " acculturée », d'une écriture profondément ambivalente. D’un côté, elle était une recension lisse, sans aspérités, des faits de nature et du gouvernement musulman des hommes. Mais d'autre part, elle faisait montre de ce qu'on pourrait appeler des «bouffées d'identité ». Des cas de conversions sont évoqués, comme d'apostasie, de martyre, comme sont signalés les moments de résurgence de la stricte dhimma. Mais elle n'expose plus, comme une plus ancienne Histoire des patriarches l'avait pratiquée, la leçon morale de ces événements touchant la communauté chrétienne d'Égypte, elle ne commente plus, elle n'attribue plus les malheurs endurés à l'anomie des Arabes ou aux péchés des chrétiens. En somme, une lecture éthique du temps présent n'y est plus visible.

Mais l'on aurait tort de croire que les milieux chrétiens d'Égypte convergeaient sur une posture commune envers les gouvernants musulmans. Sous les Fatimides puis les Ayyoubides, les évêques de la basse vallée du Nil et les notables chrétiens associés au pouvoir musulman se partageaient, d'un côté, le gouvernement de l'Église copte, et, de l'autre, le patronage des églises et des monastères qui environnaient les centres urbains, Le Caire en premier lieu. C'est au sein de ce milieulà que l'Histoire des patriarches d'Alexandrie était élaborée, et cette Histoire rendait malaisément compte d'une situation complexe, qui était, pour la communauté chrétienne, de discrimination et de perte des âmes, et, pour le milieu des notables chrétiens, de proximité au pouvoir musulman. Nous ne pouvons que résumer ici ce qui appellerait à de longues démonstrations (Den Heijer, 1996 ; Décobert, 2005) : l'ambivalence de l'écriture historiographique chrétienne, dans son assimilation parfaite à l'historiographie musulmane mais avec ses éclats d'expressions identitaires, reflète surtout les tensions de son milieu de production. Ailleurs, en Haute et Moyenne-Égypte, dans le Delta, les monastères et les évêchés étaient totalement exclus du pouvoir ecclésial. Mais, au vrai, ils étaient devenus, depuis les Fâtimides et encore plus sous les premiers Ayyoubides, les lieux de dépôt de l'antique tradition chrétienne. Et, au nom même de cette tradition, les lieux d'un autre discours possible.

C'est de cet autre milieu, de plus en plus éloigné de la maîtrise du présent, que provient le martyre de Jean de Phanidjôit. Proprement, le monastère de Saint-Macaire, dans le Delta occidental, où le martyre fut rédigé, était l'un des hauts lieux de ce conservatoire de la tradition. La composition du martyre de Jean n'est certainement pas le fait d'une seule mais de deux plumes, d'un certain Marc, qui dit avoir enquêté, recueilli les informations sur le martyre, et d'un certain Pierre, qui dit avoir écrit le texte. L'encomium est composé de deux parties : le sermon qui constitue le discours moral du texte et la narration proprement dite du martyre ; la première partie participant de la facture très classique, grandiloquente et émaillée de citations scripturaires, de l'apologétique chrétienne, 
la seconde étant d'un style narratif beaucoup plus direct, attentif au détail, au réalisme de la description concrète. Notre hypothèse a été la suivante (2005): un certain Marc a produit une narration en arabe, et sur cette base un texte copte a été élaboré, formé à la fois d'un sermon directement écrit en copte (et formant la partie première, éminemment doctrinale) et du récit traduit de l'arabe. Mais si le martyre a été rédigé en copte, ce n'est certainement pas parce qu'il fallait "écrire caché ", recourir au hidden transcript; l'on sait bien que les "bouffées d'identité », qui parsemaient l'historiographie chrétienne et constituaient certains opuscules (par exemple, Labib, 1982), étaient toujours écrites dans la langue désormais commune, l'arabe, donc accessibles à une autorité musulmane qui montrait une grande indifférence à ces soubresauts littéraires. Mais le copte était bien la langue de la tradition. Et de la réaction. La production de ce texte réactif n'a pas été celle d'une supposée "Chrétienté égyptienne ", mais d'un milieu très spécifique. Un milieu où l'on pouvait encore (c'est le thème central de la première partie, doctrinale, du martyre) donner un sens moral aux malheurs du temps : parler des Arabes comme d'hommes sans foi ni loi, expliquer l'arabisation des chrétiens comme une contamination, une pollution, évoquer la femme musulmane du converti Jean de Phanidjôit comme une terrible séductrice.

Et pourtant, un tel texte ne pouvait chasser totalement le réel, celui-ci revenait au galop... Lorsque Jean est présenté devant le sultan Al-Malik al-Kâmil, il le reconnaît comme son roi, demandant à Dieu de consolider son pouvoir. Puis il lui dit en substance ceci : je suis chrétien, mais j’ai renié Jésus ; tu es juste, fais-moi don de ma foi, je suis impur, purifie-moi ; autrement dit : si tu me fais mourir, selon ta loi, tu reconnais par là que je suis chrétien, et tu me rends à ma foi chrétienne. Mais signifiant cela, Jean concède au sultan la disposition de la loi. La séduction ultime des Arabes n'est-elle pas de passer, aux yeux des chrétiens, pour un peuple de droit ? Le médecin chrétien Abû Shâkir, qui tentait de dissuader Jean d'affronter le sultan, l'affirmait bien : si Jean a commis la faute de se convertir à l'islam, c'est par rapport à des valeurs strictement chrétiennes que cette faute devait être jugée, et la rémission ne pouvait se faire que dans le monde chrétien. La pire des illusions était de s'en remettre au système musulman des valeurs...

Christian DÉCOBERT CEIFR, CNRS-EHESS

Albert Jean-Pierre, 2001, "Sens et enjeux du martyre : de la religion à la politique ", in Pierre Cenntlivres, (éd.), Saints, sainteté et martyre. La fabrique de l'exemplarité, Neufchâtel - Paris, Éditions de l'Institut d'ethnologie - Éditions de la Maison des sciences de l'homme, pp. 17-25.

Al-Makin IBN AL-'Amid, 1994, Chronique des Ayyoubides (602-658/1205-6-1259-60), trad. annotée par Anne-Marie EdDÉ \& Françoise Micheau, Paris, Académie des Inscriptions et Belles-Lettres. 
AmÉLINEAu Émile, 1887, «Un document copte du XIII e siècle. Martyre de Jean de Phanidjôit ", Journal asiatique, février-mars, pp. 113-190.

BAfFioni C., 2004, "The Concept of Nature in Yahyā (A Comparison with the Ikhwān al-Safā') ", in Ebied Rifaat \& Herman Teule, (éds.), Studies on the Christian Arabic Heritage, Leuven, Peeters, pp. 199-204.

Balestri I. \& Hyvernat H., 1924, Corpus Scriptorum Christianorum Orientalium (= CSCO) 86, Louvain, Peeters, pp. 157-182.

BELIN M., 1851, "Fetoua relatif à la condition de zimmis, et particulièrement des Chrétiens, en pays musulmans, depuis l'établissement de l'islamisme, jusqu'au milieu du $8^{\mathrm{e}}$ siècle de l'Hégire ", Journal asiatique, 4e série, 17, pp. 417-513.

Casanova Paul, 1901, "Notes sur un texte copte du XIII siècle », Bulletin de l'Institut français d'archéologie orientale 1, pp. 113-137.

CATlos Brian, 1996, "To Catch a Spy: The Case of Zayn al-Dîn and Ibn Dukhân », Medieval Encounters 2, pp. 99-113.

DÉCOBERT Christian, 1992, "Sur l'arabisation et l'islamisation de l'Égypte médiévale ", in Décobert C., (éd.), Itinéraires d'Égypte. Mélanges offerts au père Maurice Martin, Le Caire, IFAO, pp. 293-294.

DÉCOBERT Christian, 2005, «Le martyre de Jean de Phanidjôit ", Mélanges de l'Université Saint-Joseph 58, pp. 441-473.

Den Heijer Johannes, 1996, "Coptic Historiography in the Fātimid, Ayyūbid and Early Mamlūk Periods ", Medieval Encounters 2, pp. 67-98.

Ebied Rifaat \& David Thomas (éds.), 2005, Muslim-Christian Polemic during the Crusades. The Letter from the People of Cyprus and Ibn Abī Tălib al-Dimashqù's Response, Leiden, Brill.

Ebied Rifaat \& Herman Teule, (éds.), 2004, Studies on the Christian Arabic Heritage, Leuven, Peeters.

El-Leithy Tamer, 2006, "Sufis, Copts and the Politics of Piety. Moral Regulation in Fourteenth-Century Upper Egypt ", in Mc Gregor Richard \& Adam SAbra, (éds.), Le développement du soufisme en Égypte à l'époque mamelouke, Le Caire, IFAO, pp. 75-119.

Flusin Bernard, 1991, « Démons et Sarrasins. L'auteur et le propos des Diègèmata stèriktika d'Anastase le Sinaïte ", Travaux et mémoires 11, pp. 381-409.

Gimaret Daniel, 1980, Théories de l'acte humain en théologie musulmane, Paris, Vrin.

GotTHEIL Richard, 1921, "An Answer to the Dhimmis ", Journal of the American Oriental Society 41, pp. 383-457.

Grabar Oleg, 1959, "The Omeyyad Dome of the Rock in Jerusalem », Dumbarton Oaks Papers 3, pp. 33-62.

GrIFFITH Sidney H., 2004, "Apologetics and Historiography in the Annals of Eutychius of Alexandria: Christian Self-Definition in the World of Islam ", in EBIED Rifaat \& Herman Teule, (éds.), Studies on the Christian Arabic Heritage, Leuven, Peeters, pp. 65-89.

GrIfFITH Sidney H., 2005, «Answering the Call of the Minaret: Christian Apologetics in the World of Islam ", in Van Ginkel J.J., H.H.L. Murre-Van den Berg \& T.M. van LINT, (éds.), Redefining Christian Identity. Cultural Interaction in the Middle East since the Rise of Islam, Leuven, Peeters, pp. 91-126.

GRIL Denis, 1980, "Une émeute anti-chrétienne à Qûs au début du VIII $/ \mathrm{XIV}^{\mathrm{e}}$ siècle ", Annales islamologiques 16, pp. 241-274. 
i 6 - ARChives DE SCIENCES SOCIALES DES RELIGIONS

Guillaume Alfred, 1955, The Life of Muhammad. A Translation of Ibn Ishaq's Sirat Rasul Allah, Oxford, Oxford University Press.

Harrak Amir, 2005, "Ab! The Assyrian is the Rod of my Hand! Syrian view of History after the Advent of Islam ", in Van Ginkel J.J., H. H.L. Murre-Van den Berg \& T.M. van LinT, (éds.), Redefining Christian Identity. Cultural Interaction in the Middle East since the Rise of Islam, Leuven, Peeters, pp. 45-65.

Hyvernat Henri, 1950 (révision de L.Th. Lefort), Acta Martyrium II, CSCO 125, Leuven, Peeters, pp. 108-125.

Khater Antoine \& Khs-Burmester O.H.E, (éds.), 1970, History of the Patriarchs of the Egyptian Church, III/2, Le Caire, Publications de la Société d'archéologie copte IFAO, pp. 166-225.

LabIB Subhi, 1982, "Ein Koptischer Märtyrer des 13. Jhdts.: Al-Hạīs Būlus Ar-Rāhịib al-Qibtī ", in Samir Khalı, (éd.), Actes du premier congrès international d'études arabes chrétiennes, Orientalia Christiana Analecta 218, pp. 234-240.

Maccoull Leslie S.B., 2000, « Notes on the martyrdom of John of Phanijoit (BHO 519) », Medieval Encounters 6, pp. 59-79.

Martin Maurice, 1985, "Une lecture de l'Histoire des patriarches d'Alexandrie ", Proche-Orient chrétien 35, pp. 15-36.

Morony Michael G., 2005, "History and Identity in the Syrian Churches ", in VaN Ginkel J.J., H.H.L. Murre-Van den Berg \& T.M. van Lint (éds.), Redefining Christian Identity. Cultural Interaction in the Middle East since the Rise of Islam, Leuven, Peeters, pp. 1-33.

Omar Hanaa H. Kilany, 2001, Apostasy in the Mamluk Period: The Politics of Accusations of Unbelief, PhD Dissertation, Philadelphia, University of Pennsylvania.

Perlmann Moshe, 1940-42, "Notes on Anti-Christian Propaganda in the Mamlūk Period ", Bulletin of the School of Oriental and African Studies 10, pp. 843-861.

PINES Shlomo, 1996, "Yahyā Ibn 'Adī's Refutation of the Doctrine of Acquisition (Iktisāa) ", Studies in the History of Arabic Philosophy, The Collected Works of Shlomo Pines 3, Jérusalem, pp. 110-155.

Platti Emilio, 2004, "Yahyā Ibn 'Adî. Réflexions à propos de questions de kalām musulman ", in Ebied Rifaat \& Herman Teule, (éds.), Studies on the Christian Arabic Heritage, Leuven, Peeters, pp. 177-197.

Richard Jean, 1996, Histoire des croisades, Paris, Fayard.

Sivan Emmanuel, 1967, "Notes sur la situation des chrétiens à l'époque ayyoubide ", Revue de l'histoire des religions 127, pp. 117-130.

Strauss E., 1950, "L'inquisition dans l'État mamlouk », Rivista degli Studi Orientali 25, pp 11-26.

SuERMANN Harald, 2004, "Koptische arabische Apokalypsen », in EBIED Rifaat \& Herman Teule, (éds.), Studies on the Christian Arabic Heritage, Leuven, Peeters, pp. 25-44.

Thomas David, 2004, «A Mu'tazilî Response to Christianity: Abū 'Alî al-Jubbā'î̀'s Attack on the Trinity and Incarnation ", in Ebied Rifaat \& Herman Teule, (éds.), Studies on the Christian Arabic Heritage, Leuven, Peeters, pp. 279-313.

Thomas David, 2005, "Explanations of the Incarnation in Early 'Abbasid Islam », in Van Ginkel J.J., H.H.L. Murre-Van den Berg \& T.M. van Lint, (éds.), Redefining Christian Identity. Cultural Interaction in the Middle East since the Rise of Islam, Leuven, Peeters, p. 127-149. 
Thomson Robert W., 2005, " Christian Perception of History - The Armenian Perspective », in Van Ginkel J.J., H. H.L. Murre-Van Den Berg \& T.M. van Lint, (éds.), Redefining Christian Identity. Cultural Interaction in the Middle East since the Rise of Islam, Leuven, Peeters, pp. 35-44.

Troupeau Gérard, 2004, "Notes sur deux versions arabes de l'entretien du catholicos Timothée I avec le calife al-Mahdî », in EbIEd Rifaat \& Herman Teule, (éds.), Studies on the Christian Arabic Heritage, Leuven, Peeters, pp. 217-220.

Van Ginkel Jan J., 2005, « History and Community. Jacob of Edessa and the West Syrian Identy ", in Van Ginkel Jan J., H.H.L. Murre-Van den Berg \& Theo M. van Lint, (éds.), Redefining Christian Identity. Cultural Interaction in the Middle East since the Rise of Islam, pp. 67-75.

Van Ginkel Jan J., Heleen H.L. Murre-Van den Berg \& Theo M. van Lint, (éds.), 2005, Redefining Christian Identity. Cultural Interaction in the Middle East since the Rise of Islam, Leuven, Peeters.

Van Nispen Tot Seveenaer Christian, 1996, Activité humaine et agir de Dieu, Beyrouth, Dar el-Machreq.

Watt John W., 2005, «The Strategy of the Bagdad Philosophers. The Aristotelician Tradition as a Common Motif of Christian and Islamic Thought ", in VAN GINKEL J.J., H.H.L. Murre-Van den Berg \& T.M. van Lint, (éds.), Redefining Christian Identity. Cultural Interaction in the Middle East since the Rise of Islam, Leuven, Peeters, pp. 151-165.

Zaborowski Jason R., 2005, The Coptic Martyrdom of John of Phanijôit. Assimilation and Conversion to Islam in Thirteenth-Century Egypt, Leiden, Brill. 